\title{
COVID-19 in the Intravitreal Injection (IVI) Procedure at a Spanish Urban Tertiary Hospital
}

Jonathan Jesús Cancelliere Fernández ( $\square$ jonathancf91@gmail.com )

Hospital Universitario de la Princesa https://orcid.org/0000-0001-7442-260X

María Muxima Patricia Acebes García

Hospital Universitario de la Princesa

Francisco Javier Moreno-Alemán Sánchez

Hospital Universitario de la Princesa

J. Jacobo González-Guijarro

Hospital Universitario de la Princesa

\section{Research Article}

Keywords: COVID-19 disease, intravitreal anti-angiogenic injections, macular disease.

Posted Date: June 15th, 2021

DOI: https://doi.org/10.21203/rs.3.rs-526020/v1

License: (1) (1) This work is licensed under a Creative Commons Attribution 4.0 International License. Read Full License 


\section{Abstract}

Purpose: To describe the rate of COVID-19 in intravitreal injection (IVI) procedure at the onset of the pandemic.

Methods: This transversal, observational and retrospective study included patients treated with IVI, in 3 groups. A: from February 20 to March 15, 2020, a period prior to lockdown and the first preventive measures against viral transmission. B: from March 16 to May 3, after the start of both, and C: from May 4 to June 19, after lockdown. Age, sex, diagnosis, drug, IVI laterality, visual acuity, percentage of single eyes, date of COVID-19 diagnosis, incidence among the Hospital attended population and number of COVID-19 patients admitted daily, were collected.

Results: 1049 patients were treated, 564 (53.7\%) on two or more occasions. COVID-19 rate was 1.51\% (8/529) in group A, 0.21\% (1/469) in B and $0 \%$ in $\mathrm{C}(0 / 926)(\mathrm{p}=0.0001)$. The highest incidence peak $\times 10^{5}$ inhabitants and the mean daily admission rate, for the periods corresponding to the three groups, were 93.70/7.70 (SD 7.32), 418.72/27.83 (SD 24.68) and 24.58/2.28 (SD 1.97), respectively.

Conclusion: The favourable trend in the COVID-19 rate among our patients, after implementing preventive measures against viral transmission, may assist in adequately planning IVI procedure in the future.

\section{Key Message}

- Several scientific societies have issued recommendations for managing different retinal pathologies during the pandemic.

- The percentage of COVID-19 cases among our patients treated with intravitreal anti-angiogenic injections at the beginning of the pandemic was significantly smaller $(0 \%-0.21 \%)$ after implementing preventive measures against the transmission of the virus than before taking these measures $(1.51 \%)$.

- The favourable trend in the COVID-19 rate among our patients, after implementing preventive measures against viral transmission, may assist in adequately planning IVI procedure in the future.

\section{Introduction}

The coronavirus disease 2019 (COVID-19) caused by SARS-COV-2 (severe acute respiratory syndrome coronavirus 2) usually involves respiratory and enteric infections. Its high infectivity and transmission rate has led the World Health Organization (WHO) to declare it an international pandemic [1]. Spain is currently one of the most heavily affected countries. The first case was recorded on 24 February 2020 in the Autonomous Community of Madrid (CAM), where the number of cases has been greater than the Spanish average [2]. On Saturday 14 March 2020, with the aim of preventing the virus from spreading, the Spanish government implemented, among other measures, the home confinement rule (lockdown) that was maintained within the CAM until 4 May. As of that date, activity and mobility restrictions were gradually reduced and on 21 June they ended [3]. Most of the public and private hospitals throughout the CAM have been obliged to dedicate a large part of their resources to assisting patients affected by COVID-19. Thus, many members of the various Ophthalmology Services have taken part in providing hospital care for these patients. The activity of other ophthalmologists was focused on ophthalmological emergencies, and on reorganising and establishing priorities among the regular patients' pathologies at each ophthalmological unit. Intravitreal injection (IVI) of anti-angiogenic drugs, is currently one of the most frequent ophthalmological procedures, and poses a considerable organizational challenge under the present pandemic conditions. Of the retinal diseases these are used for, exudative age-related macular degeneration (AMD), with an estimated prevalence in our environment of $10.3 \%$ in adults over 65 years, is the most common indication [4]. Even under more stringent transmission prevention measures, deciding whether or not to maintain the necessary treatment in these older patients who are at greater morbidity/mortality risk from COVID-19, poses a dilemma since the beginning of the pandemic [5], in the knowledge that any interruption is liable to cause irreversible loss of visual acuity (VA) [6, 7]. Several scientific societies have issued recommendations for managing different retinal pathologies during the pandemic, in an effort to combine methods for preventing viral transmission while providing the best treatment in each case [8-10]. The risk of infection by SARS-COV-2 following surgery under general anaesthetic has been described [11], and also that the virus may be present in the tears of patients actively suffering COVID-19 disease while, by contrast, it seems unlikely that phacoemulsification and vitrectomy are potentially infectious procedures [12]. Despite the fact that fewer patients attended to receive IVI treatment during the initial pandemic period $[13,14]$, no information is available regarding the incidence of cases of COVID-19 among patients undergoing ophthalmological procedures excluding surgery.

The aim of this study is to describe the percentage of confirmed cases of COVID-19 in patients treated with IVI procedures at the onset of the COVID-19 pandemic, at an urban University Hospital in Madrid, before and after the establishment of measures designed to minimise the risk of transmission.

\section{Methods}

An observational, cross-sectional, retrospective and unicentric study was designed including patients scheduled for IVI at the Hospital Universitario de la Princesa (HUP) Ophthalmological Service from 20 February to 19 June 2020. Being a retrospective study consisting of a review of clinical

Page $2 / 10$ 
histories no authorisation from the HUP ethics committee was required. HUP is a tertiary Hospital including all general specialities except Obstetrics, Gynecology and Pediatrics, located in the central area of the city of Madrid. Its area of influence encompasses the districts of Salamanca, Chamartín and Ciudad Lineal, subdivided into 11 healthcare zones. On 1 January 2019 this covered 328,835 inhabitants, almost $10 \%$ of the total population of the capital, with a mean life expectancy of 84.81 years in the district of Salamanca -greater than the mean for the capital as a whole- and a socioeconomic level likewise greater than the mean within the CAM [15].

In our Service, the IVI were usually administered in a clean room in the vicinity of the ophthalmological operating theatres, following a protocol based on the best scientific evidence [16-18]. Stated briefly, two recliner chairs were used to facilitate administration and the patient was prepared wearing a disposable gown, cap, foot-cover and surgical mask. The injection was given by an ophthalmologist or resident wearing sterile gloves, surgical mask and in aseptic conditions using adhesive aperture drapes and a single-use blepharostat. Washing the patient's hands with alcohol solution before entering and after leaving the room, was adopted in February 2020. From 16 March 2020 this procedure was transferred to different clean rooms in areas free from COVID-19, as close as possible to the Hospital entrance. From then on a single recliner chair was used, covered with a disposable sheet for each patient in view of the scarcity of hospital gowns, the use of which was thenceforth discontinued. The anaesthetic eye drops and $5 \%$ povidone iodine solution were administered by a nurse or nursing assistant with the patient in a recumbent position, avoiding contact with the eyelids and disposing of any containers that come into contact with. The use of FFP2 masks (individual protective equipment) including goggles and/or eye protection screens, both by doctors administering the injection and the nursing staff participating in the procedure, was adopted. From this date patients were called 48 hours in advance to confirm they were asymptomatic (temperature, cough, breathing difficulty, fatigue, muscular pain, anosmia and/or diarrhoea) and that they had not experienced high-risk contact. They were subsequently given a confirmed appointment for the injection, and recommended to report unaccompanied. Patients requiring revision and possible intravitreal treatment were given appointments for both procedures on the same day.

From all the patients thus scheduled, in addition to age and sex, the following clinical data were collected:

- Diagnosis, bilateral patients scheduled with a different diagnosis for each eye were included under "others" for statistical analysis purposes.

- Best corrected visual acuity (BCVA) or using a pinhole occlude on the eye with best VA, scheduled for IVI, measured on the date of the IVI indication, using the ETDRS (Early Treatment Diabetic Retinopathy Study) eye chart (Precison Vision $\left.{ }^{\circledR}\right)$.

- Date on which the IVI was scheduled or administered and drug programmed; if different for each eye, this was recorded under "combinations".

- Uni or bilaterality.- Single functioning eye presence: at least one of the eyes, scheduled or not for treatment, with decimal BCVA $\leq 20 / 200$.

Among patients treated, once excluded those already diagnosed, the date of COVID-19 diagnosis was recorded up until 25 days after the last IVI, taking into account the maximum incubation and diagnosis times according to Spanish health authorities and WHO criteria [19-21]. Patients who attended on more than one occasion for treatment, were considered as independent events. Finally, if any, severe complications arising from the IVI procedure: endophthalmitis, retinal detachment and/or lens damage, were collected.

The data were extracted from the HUP computerized medical history (DXC-HCIS).® To obtain information on COVID-19, the SNS (National Health System) Digital Clinical History was also used through the Horus ${ }^{\circledR}$ computerized platform. This records healthcare reports on assistance given in Primary, Specialist, and/or Madrid Emergency Medical Service (SUMMA) care throughout the CAM. All patients with COVID-19 were contacted by telephone to re-schedule appointments for future injections and to complement, with the patients or their relatives, information on their circumstances, the evolution of their infection and any potential high-risk exposure prior to their diagnosis.

Patients receiving IVI treatment, were divided into three groups depending on the dates scheduled for it. Group A: from 20 February to 15 March. Group B: from 16 March, on which date -the first working day after the beginning of lockdown- the IVI protocol was modified, to 3 May. Group C: from 4 May, the date on which lockdown was lifted and mobility restrictions were gradually eased within the CAM, to 19 June, the last working day for administering IVI before the date on restrictions ended. COVID-19 infection rate data in the 11 basic healthcare zones from 20 February to 19 June 2020, were gathered from the epidemiological information issued by the CAM, which published a weekly report on the incidence over each fortnightly period and the accumulated total [22]. Data on daily admission of COVID-19 patients at the HUP were obtained from the Admissions and Clinical Documentation Service.

The statistical analysis was performed with the software Stata v.15 (Stata corp USA®). Continuous data are presented as mean and standard deviation for normally distributed data. Categorical data are presented as a percentage (\%). Categorical variables were compared using a chisquare test or Fisher's exact test, and continuous variables were compared using a two-sample t-test. Previous homoscedasticity was analysed using Levene's test. Values of $\mathrm{P}<0.05$ were considered of statistical significance.

\section{Results}


During the period studied 1139 patients were scheduled to receive IVI treatment (Fig. 1). Mean age was 80.41 (SD 10.46) years, of which 62.5\% were women; treatment was prescribed unilaterally in 78\%; the most frequent pathology was AMD (75\%), followed by diabetic macular edema (9.6\%) and retinal vein occlusions (7.4\%); average BCVA was logMAR 0.47 (SD: 0.39); and 39.1\% of patients had a single functioning eye (Table 1). Of the total number of patients scheduled for treatment, 1049 (92.1\%) received IVI of which 564 (53.7\%) did so on two or more occasions. All 3 groups were homogeneous, except in age: patients in group B (77.53, SD 10.52 years), were comparatively younger than patients in groups $A$ $(80.24$, SD 10.11) and C (80.19, SD 10.28) $(p=0.00001)$ (Table 2). In group A, 1.51\% (8/529) were diagnosed with COVID-19, in group B 0.21\% $(1 / 472)$ and in group C $0 \%(0 / 974)(p=0.0001)$. Mean time elapsed between the IVI procedure and diagnosis was 19.11 (SD 4.31$)$ days. Five patients in group A experienced high-risk contacts in their home environment after the procedure, 8 patients needed admission to hospital and 2 patients died of COVID-19 related complications (Table 3). After 2367 injections, no severe ocular complications were observed. The infection rate of COVID-19 in the HUP basic healthcare zones for the duration of this study are shown in Fig. 2. Mean daily COVID-19 hospital admissions are given in Table 2.

\section{Discussion}

In a highly infectious disease such as COVID-19, establishing the risk of transmission deriving from a specific healthcare procedure would normally require repeatedly conducting seroprevalence and PCR detection studies, both on patients and healthcare staff, and comparing these with a similar population not involved in the procedure. Nevertheless, in such conditions it would still be difficult to establish a relationship between the procedure and the transmission of the SARS-COV-2, given that the opportunities for this to occur may overlap, and susceptibility to infection may vary among patients, instances of exposure and the healthcare professionals conducting the procedure. To address this difficulty, we designed this study to satisfy the need to obtain information that would allow us to achieve, albeit indirectly, safe conditions regarding SARSCOV-2 for a procedure that is applied so frequently and with such implications as anti-angiogenic IVI.

In this line, although no data have been published to date in Spain, and as happening in other countries, most of the IVI in our environment featuring an accessible and universal public health system, are conducted within the SNS [23]. Although the population treated at the HUP enjoys higher income levels than the mean for the city of Madrid, our experience shows that a large proportion of patients who initiated their intravitreal anti-angiogenic therapy without the SNS, eventually reverted to it to continue their treatment owing to high medication costs, not included in the majority of Spanish private health insurance policies. We believe, therefore, that the sample plausibly represents the population receiving this treatment in environments similar to ours.

We obtained data on confirmed cases of infection both from our computerized medical history, and from the online platform recording healthcare reports at all levels of the SNS within the CAM. In our view, this approach has allowed us to adequately calculate the confirmed rate of COVID-19 in patients treated with IVI at our Hospital. Two of these patients were, in fact, assisted at other hospitals, one of which is a private institution. But throughout the CAM, all outpatient management of the infection is being handled through the Primary Care SNS network. So, the mentioned platform, has allowed us to access to the relevant COVID-19 related healthcare reports. Taking into account the maximum incubation and diagnosis periods from the onset of symptoms, at the date on which the study commenced, and acknowledging the risk of over-estimating the possible relationship with the procedure, cases were recorded up to 25 days after the IVI. Thus, 5 of the 8 confirmed infections reported contacts within the family environment after the procedure, a situation that has been associated to most cases of infection in several publications, including the population study of seroprevalence in Spain (ENE COVID) conducted in the same time-frame as ours [24, 25].

Studying the rate of COVID-19 in our patients over four months - the period considered as the first wave- and, as indirect measures of the SARSCOV-2 infection load, both the incidence among the population in our healthcare zones and the number of hospital admissions, has given us insights on the evolution of the rate in our IVI procedure. This was achieved despite changing diagnostic protocols and criteria applied to the conduct of diagnostic tests over these 4 months, which affected the incidence rates obtained. We believe that the significant drop in the percentage of COVID-19 among our patients during the course of the study, allows us to interpret that the therapy changes implemented, jointly with the general public health measures taken, may have contributed to enhancing the safety of this procedure, with regard to the risk of infection by SARS COV-2. This is suggested by the significant decrease in the percentage of patients infected in group B, at a time of high SARS-COV-2 infection load in the environment. It has recently been described that the respitratory transmission is the main infection route [26], which leads us to believe that the recommended measures implemented to avoid infection, namely the use of face-masks, appropriate ventilation, regulating the flow of patients, and hand-washing, may have been effective and contributed to allowing us to conduct this procedure safely during the period studied.

As has been described, the number of patients attending to receive treatment dropped during the period of lockdown [27]. On the one hand, the age of patients seeking treatment in our sample was lower, which may point either to greater caution among older patients, or to greater difficulties for travelling at a time of mobility restrictons. On the other hand, higher percentages of AMD and bi-laterality among patients attending for treatment were observed, leading us to suspect stronger motivation or awareness of the need to receive IVI. Indeed, over one-half of the patients came twice or more for treatment, without any increase in the number of affected individuals. The higher VA registered among patients coming for treatment is possibly secondary to the study design.

Page $4 / 10$ 
No comparisons can be drawn with our findings as there are no similar publications. Boyd et al. [23] have conducted an estimation of safety in this procedure in patients with AMD, in different scenarios regarding community prevalence and risk of VA loss. They conclude that the risk deriving from potential transmission of the virus during the procedure, in situations with community rate of transmission figures similar to ours, is less severe than the risk of loss of VA arising from failing to receive IVI. Thus, in real life terms, our results seem to bear out their appraisal that this procedure is safe. Relocating the site of administration to other clean rooms has not given rise to significant infection hazards, although a greater number of IVI would be necessary to determine the actual influence of this parameter.

The study is not free from some limitations that may have underestimated the incidence of COVID-19. On the one hand, its design does not allow us to quantify the percentage of asymptomatic or paucisymptomatic patients who did not require medical assistance. During the time-frame for group B, the prevalence of sero-positive cases in the CAM was 11.3\%, among the highest in Spain, of which 30\% were asymptomatic [24]. On the other hand, no naso-pharyngeal PCRs were performed, although their usefulness in detecting asymptomatic patients among those scheduled for IVI treatment or procedures viewed as low risk of transmission, is poor $(<1 \%)[28,29]$. Likewise, our results do not include an analysis of the possible infection and transmission among the healthcare staff involved in the procedure, who, in our facility, were equipped from the outset with the recommended preventive measures for conducting the procedure and did not combine with the staff providing care to COVID-19 patients. In addition, the COVID-19 rate may be underestimated in the HUP's healthcare zones, as both diagnostic protocols and the criteria for conducting diagnostic tests were subject to changes throughout the duration of the study.

In summary, the findings of this study describe, for the first time in the real world, the evolution of COVID-19 rates among patients receiving IVI before and after implementing the recommended measures for reducing the risk of virus transmission, under different SARS-COV2 infection load situations. These data may prove of assistance in defining criteria for planning this frequent procedure, with the established precautions, throughout the unpredictable duration of the pandemic in environments similar to our own, thus enabling us to respond safely and adequately to our patients' needs.

\section{Declarations}

Funding The authors did not receive support from any organization for the submitted work.

Availability of data and material Not applicable.

Code availability Not applicable.

Ethics approval The study was in adherence to the tenets of the Declaration of Helsinki. This is an observational study. The instutional Research Ethics Committee has confirmed that no ethical approval is required.

\section{Conflicts of interest/Competing interests}

The authors have no relevant financial or non-financial interests to disclose.

\section{Consent to participate}

Not applicable.

\section{Consent for publication}

Not applicable.

\section{References}

1. World Health Organization (2020) Coronavirus disease (COVID-19) Situation Report - 176. 14 July. https://www.who.int/docs/defaultsource/coronaviruse/situation-reports/20200714-covid-19-sitrep-176.pdf?sfvrsn=d01ce263_2. Accessed November 30, 2020

2. Consejería de Sanidad, Comunidad de Madrid (2020) Datos COVID-19. 14 de julio. https://www.comunidad.madrid/sites/default/files/doc/sanidad/200714_cam_covid19.pdf. Accessed December 10, 2020

3. de Sanidad M, Gobierno de España (2020) Plan para la transición hacia una nueva normalidad. https://www.lamoncloa.gob.es/consejodeministros/resumenes/Documents/2020/PlanTransicionNuevaNormalidad.pdf. Accessed November 9, 2020

4. Casaroli-Marano R, Piñero A, Adan A et al (2011) Prevalence of age-related macular degeneration in Spain. Br J Ophthalmol 95:931-936. http://dx.doi.org/10.1136/bjo.2010.187773

5. Antaki F, Dirani A (2020) Treating neovascular age-related macular degeneration in the era of COVID-19. Graefes Arch Clin Exp Ophthalmol 68 https://doi.org/10.1007/s00417-020-04693-w 
6. Mitchell P, Liew G, Gopinath B, Wong TY (2018) Age-related macular degeneration. Lancet 392:1147-1159. https://doi.org/10.1016/S01406736(18)31550-2

7. Wong T, Chakravarthy U, Klein R et al (2008) The Natural History and Prognosis of Neovascular Age-Related Macular Degeneration. A Systematic Review of the Literature and Meta-analysis. Ophthalmology 115:116-127. https://doi.org/10.1016/j.ophtha.2007.03.008

8. Korobelnik JF, Loewenstein A, Eldem B et al (2020) Guidance for anti-VEGF intravitreal injections during the COVID-19 pandemic. Graefe's Arch Clin Exp Ophthalmol 258:1149-1156. https://doi.org/10.1007/s00417-020-04703-x

9. American Academy of Ophthalmology (2020) Important coronavirus updates for ophthalmologists. March 2020. https://www.aao.org/headline/alert-important-coronavirus-context. Accessed May 17, 2020

10. Gegúndez-Fernández JA, Llovet-Osuna F, Fernández-Vigo Jl et al (2021) Recommendations for ophthalmologic practice during the easing of COVID-19 control measures. Acta Ophthalmol 1-11 https://doi.org/10.1111/aos.14752

11. Tang LY, Wang J (2020) Anesthesia and COVID-19: What We Should Know and What We Should Do. Semin Cardiothorac Vasc Anesth 24(2):127-137. https://doi.org/10.1177/1089253220921590

12. Chandra A, Haynes R, Burdon M et al (2020) Personal protective equipment (PPE) for vitreoretinal surgery during COVID-19. Eye 34:11961199. https://doi.org/10.1038/s41433-020-0948-3

13. Viola F, Milella P, Giuffrida FP et al (2021) Impact of coronavirus disease pandemic on intravitreal injections treatment for macular diseases. Report from a referral Hospital in Milan. Retina https://doi.org 10.1097/IAE.0000000000002941

14. Wasser LM, Weill Y, Brosh K et al (2020) The Impact of COVID-19 on Intravitreal Injection Compliance. SN Compr Clin Med https://doi.org/10.1007/s42399-020-00614-4

15. Gobierno de la Comunidad de Madrid (Hospital Universitario de la Princesa. Memoria 2019) https://www.comunidad.madrid/servicios/salud/memorias-e-informes-servicio-madrileno-salud; 2019. Accessed January 17, 2021

16. Grzybowski A, Told R, Sacu S et al (2018) Update on Intravitreal Injections: Euretina Expert Consensus Recommendations. Ophthalmologica 239:181-193. https://doi.org/10.1159/000486145

17. Avery R, Bakri S, Blumenkranz S et al (2014) Intravitreal Injection Technique and Monitoring. Retina 34:S1-S18. https://doi.org/10.1097/IAE.0000000000000399

18. Gómez-Ulla de Irazazábal FJ, Barquet LA, Basauri Rementería E et al (2012) Manejo de las inyecciones intravítreas. Guías de Práctica Clínica de la SERV https://serv.es/publicaciones/guias-practica-clinica/\#1553874292280-6c155c10-95b4 Accessed May 17, 2020

19. World Health Organization (2020) Global Surveillance for human infection with coronavirus disease (COVID-19). https://www.who.int/publications-detail/global-surveillance-for-human-infection-with-novel-coronavirus-(2019-ncov) Accessed May 17, 2020

20. de Sanidad M, Gobierno de España (2020) Información científico técnica. Enfermedad por coronavirus. versión 17 Abril. https://www.mscbs.gob.es/profesionales/saludPublica/ccayes/alertasActual/nCov/ITCoronavirus/informesPrevios.htm Accessed May 13, 2020

21. Red Nacional de Vigilancia Epidemiológica (2020) Informe no 30. Situación de COVID-19 en España a 11 de mayo de 2020 . Equipo COVID-19. https://www.isciii.es/QueHacemos/Servicios/VigilanciaSaludPublicaRENAVE/EnfermedadesTransmisibles/Documents/INFORMES/Informes COVID-19/Informe no 30.Situación-de-COVID-19-en-España-a-11 de-mayo-de-2020.pdf Accessed May 13, 2020

22. Comunidad de Madrid (2020) Datos abiertos Covid-19. Tasa de Incidencia Acumulada Zonas Básicas de Salud. https://datos.comunidad.madrid/catalogo/dataset/covid19_tia_zonas_basicas_salud Accessed November 9, 2020

23. Boyd MJ, Scott DAR, Squirrell DM, Wilson GA (2020) Proof-of-concept calculations to determine the health-adjusted life-year trade-off between intravitreal anti-VEGF injections and transmission of COVID-19. Clin Exp Ophthalmol 1276-1285 https://doi.org/10.1111/ceo.13855

24. Pollán M, Pérez-Gómez B, Pastor-Barriuso R et al (2020) Prevalence of SARS-CoV-2 in Spain (ENE-COVID): a nationwide, population-based seroepidemiological study. Lancet 396:535-544. https://doi.org/10.1016/S0140-6736(20)31483-5

25. Meyerowitz EA, Richterman A, Gandhi RT, Sax PE (2020) Transmission of SARS-CoV-2: A Review of Viral, Host, and Environmental Factors. Ann Intern Med 1-12 https://doi.org/10.7326/m20-5008

26. Wiersinga WJ, Rhodes A, Cheng AC et al (2020) Pathophysiology, Transmission, Diagnosis, and Treatment of Coronavirus Disease 2019 (COVID-19): A Review. JAMA - J Am Med Assoc 324:782-793. https://doi.org/10.1001/jama.2020.12839

27. Borrelli E, Grosso D, Vella G et al (2020) Impact of COVID-19 on outpatient visits and intravitreal treatments in a referral retina unit: let's be ready for a plausible "rebound effect. Graefe's Arch Clin Exp Ophthalmol 258:2655-2660. https://doi.org/10.1007/s00417-020-04858-7

28. Schlosser M, Signorelli H, Gregg W et al (2021) COVID-19 testing processes and patient protections for resumption of elective surgery. Am J Surg 221:49-52. https://doi.org/10.1016/j.amjsurg.2020.07.009

29. Carnevali A, Giannaccare G, Gatti V et al (2020) Intravitreal injections during COVID-19 outbreak: Real-world experience from an Italian tertiary referral center. Eur J Ophthalmol 1-3 https://doi.org/ 10.1177/1120672120962032

\section{Tables}

Page 6/10 
Table 1

Patients scheduled for intravitreal injections

\begin{tabular}{|c|c|c|c|c|c|}
\hline Variable & & $1049(92 \%)^{a}$ & $90(7.9 \%)^{b}$ & Total: 1139 (100\%) & $\mathbf{P}$ \\
\hline Age (mean) & & 80.19 (SD 10.44) & 83.01 (SD 10.47) & 80.41 (SD 10.46) & $0.01^{c}$ \\
\hline \multirow[t]{2}{*}{ Sex } & Men & $397(37.8 \%)$ & $30(33.3 \%)$ & $427(37.5 \%)$ & \multirow[t]{2}{*}{$0.39^{d}$} \\
\hline & Women & $652(62.1 \%)$ & $60(66.6 \%)$ & $712(62.5 \%)$ & \\
\hline \multirow[t]{5}{*}{ Diagnosis } & AMD & $794(75.6 \%)$ & $60(66.6 \%)$ & $854(75 \%)$ & \multirow[t]{5}{*}{$0.003^{e}$} \\
\hline & DME & $91(8.6 \%)$ & $18(20 \%)$ & $109(9.6 \%)$ & \\
\hline & Vein occlusions & $76(7.2 \%)$ & $8(8.8 \%)$ & $84(7.4 \%)$ & \\
\hline & Myopic CNV & $43(4.1 \%)$ & $4(4.4 \%)$ & $47(4.1 \%)$ & \\
\hline & Others & $45(4.2 \%)$ & $0(0 \%)$ & $45(4 \%)$ & \\
\hline \multirow[t]{2}{*}{$B C V A \leq 20 / 200$} & Yes & $407(38.8 \%)$ & $38(42.2 \%)$ & $445(39.1 \%)$ & \multirow[t]{2}{*}{$0.52^{d}$} \\
\hline & No & $642(61.2 \%)$ & $52(57.8 \%)$ & $694(60.9 \%)$ & \\
\hline \multirow[t]{4}{*}{ Drug } & Bevacizumab & $354(33.7 \%)$ & $34(37.7 \%)$ & $388(34.1 \%)$ & \multirow[t]{4}{*}{$0.01^{\mathrm{e}}$} \\
\hline & Ranibizumab & $349(33.2 \%)$ & $37(41.1 \%)$ & $386(33.9 \%)$ & \\
\hline & Aflibercept & $218(20.7 \%)$ & $17(18.8 \%)$ & $235(20.6 \%)$ & \\
\hline & Combinations & $128(12.2 \%)$ & $2(2.2 \%)$ & $130(11.4 \%)$ & \\
\hline \multirow[t]{2}{*}{ Bilateral IVI } & Yes & $238(22.6 \%)$ & $13(14.4 \%)$ & $251(22 \%)$ & \multirow[t]{2}{*}{$0.07^{d}$} \\
\hline & No & $811(77.3 \%)$ & 77 (85.5\%) & $888(78 \%)$ & \\
\hline BCVA logMAR (mean) & & 0.46 (SD 0.37) & 0.63 (SD 0.49) & 0.47 (SD 0.39) & $0.0001^{\mathrm{c}}$ \\
\hline
\end{tabular}

Patients scheduled for intravitreal injections between February 20, to June 19, 2020. Patients who did ( $\left.{ }^{a}\right)$ and who didn't ( $\left.{ }^{b}\right)$ come up for treatment. ${ }^{\mathrm{C}}=\mathrm{T}_{\text {-test; }}{ }^{\mathrm{d}}=$ Chi-square test; ${ }^{\mathrm{e}}=$ Fisher's Exact; $0=$ Standard deviation or percentage. Abbreviations: AMD = Age-related macular degeneration; BCVA = Best corrected visual acuity; BCVA $\leq 20 / 200$ : Patients with BCVA $\leq 20 / 200$ Snellen in at least one eye; DME = Diabetic macular edema; IVI = Intravitreal injection; logMAR= logarithm of minimum angle of resolution; Myopic CNV = myopic choroidal neovascularization; SD = Standard deviation. 
Table 2

Patients treated with intravitreal injection.

\begin{tabular}{|c|c|c|c|c|c|c|}
\hline Variable & & $\begin{array}{l}\text { Group A: } 529 \\
(26.7 \%)\end{array}$ & $\begin{array}{l}\text { Group B: } 472 \\
(23.9 \%)\end{array}$ & $\begin{array}{l}\text { Group C: } 974 \\
(49.3 \%)\end{array}$ & $\begin{array}{l}\text { Total } 1975 \\
(100 \%)\end{array}$ & $\mathbf{P}$ \\
\hline Age (mean) & & $\begin{array}{l}80.24(S D \\
10.11)\end{array}$ & $\begin{array}{l}77.53(\mathrm{SD} \\
10.52)\end{array}$ & $\begin{array}{l}80.19(\mathrm{SD} \\
10.28)\end{array}$ & $\begin{array}{l}79.57(S D \\
10.38)\end{array}$ & $0.00001^{a}$ \\
\hline \multirow[t]{2}{*}{ Sex } & Men & $197(37.2 \%)$ & $196(41.5 \%)$ & $375(38.5 \%)$ & $768(38.8 \%)$ & \multirow[t]{2}{*}{$0.359^{b}$} \\
\hline & Women & 332 (62.7\%) & 276 (58.4\%) & 599 (61.5\%) & 1207 (61.1\%) & \\
\hline \multirow[t]{5}{*}{ Diagnosis } & AMD & $399(75.4 \%)$ & $357(75.6 \%)$ & $761(78.1 \%)$ & $1517(76.8 \%)$ & \multirow[t]{5}{*}{$0.553^{b}$} \\
\hline & DME & $51(9.6 \%)$ & 42 (8.9\%) & $73(7.4 \%)$ & $166(8.4 \%)$ & \\
\hline & $\begin{array}{l}\text { Vein } \\
\text { occlusions }\end{array}$ & 37 (6.9\%) & $39(8.2 \%)$ & $59(6 \%)$ & 135 (6.8\%) & \\
\hline & Myopic CNV & $21(3.9 \%)$ & $12(2.5 \%)$ & $36(3.7 \%)$ & $69(3.4 \%)$ & \\
\hline & Others & $21(3.9 \%)$ & $22(4.6 \%)$ & $45(4.6 \%)$ & $88(4.4 \%)$ & \\
\hline \multirow[t]{3}{*}{ COVID-19 } & Yes & $8(1.5 \%)$ & $1(0.2 \%)$ & 0 & $9(0.4 \%)$ & \multirow[t]{3}{*}{$0.0001^{c}$} \\
\hline & No & $521(98.4 \%)$ & 468 (99.1\%) & $960(98.5 \%)$ & 1949 (98.6\%) & \\
\hline & Excluded & 0 & $3(0.6 \%)$ & $14(1.4 \%)$ & $17(0.8 \%)$ & \\
\hline \multirow[t]{2}{*}{$B C V A \leq 20 / 200$} & Yes & $170(32.1 \%)$ & $174(36.8 \%)$ & $374(38.4 \%)$ & $718(36.3 \%)$ & \multirow[t]{2}{*}{$0.053^{b}$} \\
\hline & No & $359(67.8 \%)$ & $298(63.1 \%)$ & $600(61.6 \%)$ & 1257 (63.6\%) & \\
\hline \multirow[t]{4}{*}{ Drug } & Bevacizumab & $175(33 \%)$ & $133(28.1 \%)$ & $344(35.3 \%)$ & $652(33 \%)$ & \multirow[t]{4}{*}{$0.145^{c}$} \\
\hline & Ranibizumab & $213(40.2 \%)$ & 187 (39.6\%) & $357(36.6 \%)$ & 757 (38.3\%) & \\
\hline & Aflibercept & $119(22.5 \%)$ & $126(26.6 \%)$ & $231(23.7 \%)$ & $476(24.1 \%)$ & \\
\hline & Combinations & $22(4.1 \%)$ & $26(5.5 \%)$ & $42(4.3 \%)$ & $90(4.5 \%)$ & \\
\hline \multirow[t]{2}{*}{ Bilateral IVI } & Yes & $91(17.2 \%)$ & $103(21.8 \%)$ & $197(20.2 \%)$ & $391(19.8 \%)$ & \multirow[t]{2}{*}{$0.167^{b}$} \\
\hline & No & 438 (82.8\%) & 369 (78.1\%) & 777 (79.7\%) & $1584(80.2 \%)$ & \\
\hline BCVA logMAR (mean) & & 0.50 (SD 0.40) & 0.50 (SD 0.45) & 0.49 (SD 0.37) & 0.49 (SD 0.48) & $0.804^{a}$ \\
\hline $\begin{array}{l}\text { COVID-19 daily hospital } \\
\text { admissions (mean) }\end{array}$ & & 7.70 (SD 7.32) & $\begin{array}{l}27.83(\mathrm{SD} \\
24.86)\end{array}$ & 2.28 (SD 1.97) & & \\
\hline
\end{tabular}

Patients treated with intravitreal injection divided in three groups: A: from 20 February to 15 March 2020, B: from 16 march to 3 May 2020 and C: from 4 May to 19 June 2020. ${ }^{a}=$ T-test; $^{b}=$ Chi-square test; ${ }^{c}=$ Fisher's Exact; $0=$ Standard deviation or percentage. Abbreviations: AMD $=$ Agerelated macular degeneration; BCVA = Best corrected visual acuity; BCVA $\leq 20 / 200=$ Patients with BCVA $\leq 20 / 200$ Snellen in at least one eye; DME = Diabetic macular edema; IVI = Intravitreal injection; logMAR: logarithm of minimum angle of resolution; Myopic CNV = myopic choroidal neovascularization; SD= Standard deviation.

TABLE 3. Patients with COVID-19 after intravitreal injection in our study group 


\begin{tabular}{|lllllllll|}
\hline Patient & Group & Age & Sex & IVI date & Days since IVI until COVID-19 diagnosis & Risk contacts & Hospital admission & Death $^{\text {a }}$ \\
\hline 1 & A & 66 & W & $27 / 02 / 2020$ & 17 & Yes & Yes & No \\
\hline 2 & A & 87 & M & $03 / 03 / 2020$ & 15 & No & Yes & Yes \\
\hline 3 & A & 84 & W & $03 / 03 / 2020$ & 23 & No & Yes & Yes \\
\hline 4 & A & 86 & W & $06 / 03 / 2020$ & 17 & Yes & No & No \\
\hline 5 & A & 77 & M & $09 / 03 / 2020$ & 21 & Yes & Yes & No \\
\hline 6 & A & 69 & M & $09 / 03 / 2020$ & 22 & Yes & Yes & No \\
\hline 7 & A & 88 & W & $10 / 03 / 2020$ & 23 & No & Yes & No \\
\hline 8 & A & 86 & M & $11 / 03 / 2020$ & 23 & No & Yes & No \\
\hline 9 & B & 84 & W & $23 / 03 / 2020$ & 11 & Yes & No \\
\hline
\end{tabular}

Patients with COVID-19 after intravitreal injection in our study group. ${ }^{a}=$ Death by COVID-19 related complications. IVI: Intravitreal injection; $\mathrm{M}=$ Man; $\mathrm{W}=$ Woman .

\section{Figures}

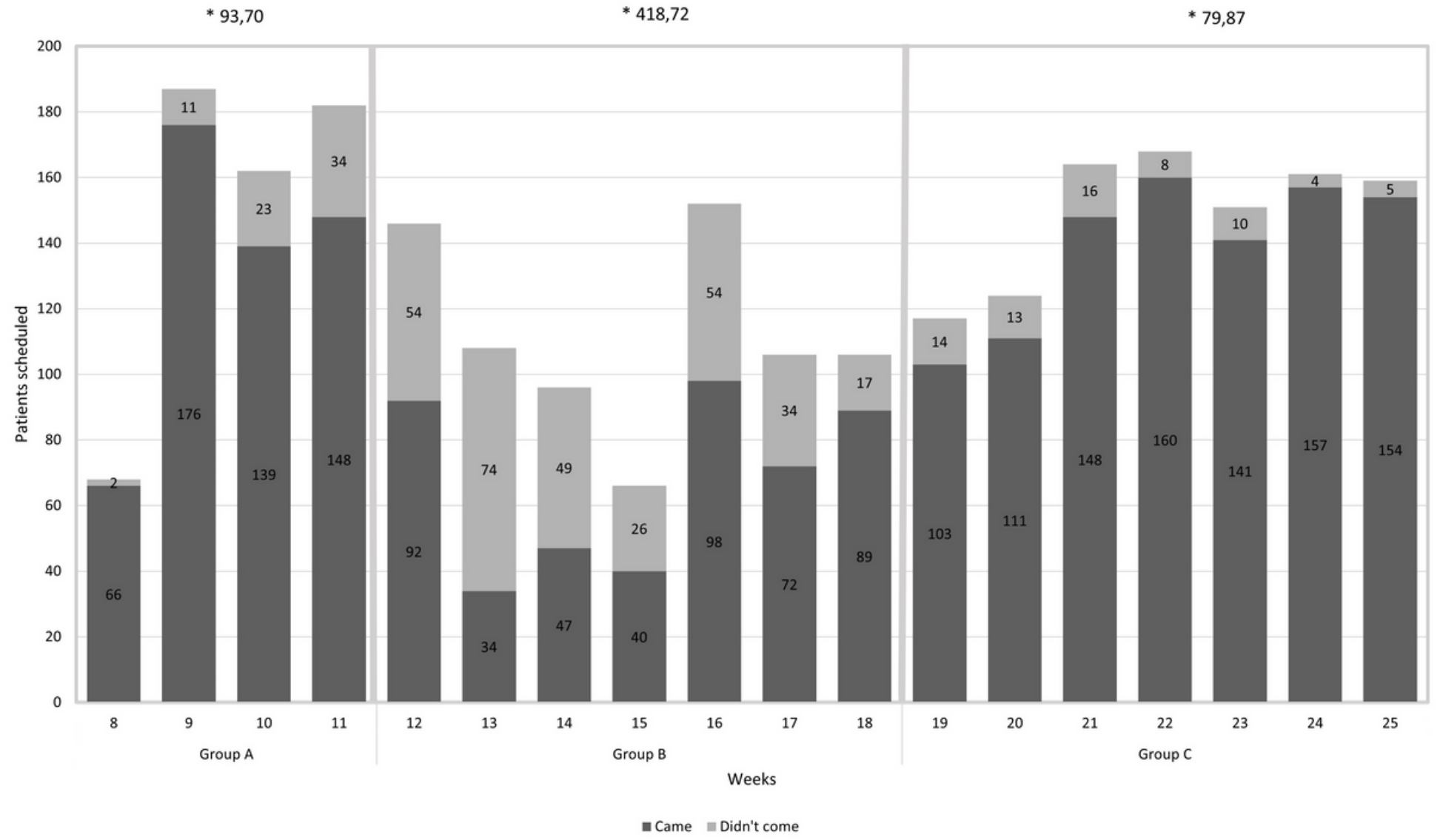

\section{Figure 1}

Patients scheduled by week for intravitreal injection. Group A: from 20 February to 15 March 2020, group B: from 16 march to 3 May 2020 and group C: from 4 May to 19 June 2020. Dark gray: Came; light gray: didn't come.*= Maximum (peak) fourteen-day incidence rate of COVID-19 x100.000 inhabitants in the Hospital basic healthcare zones 


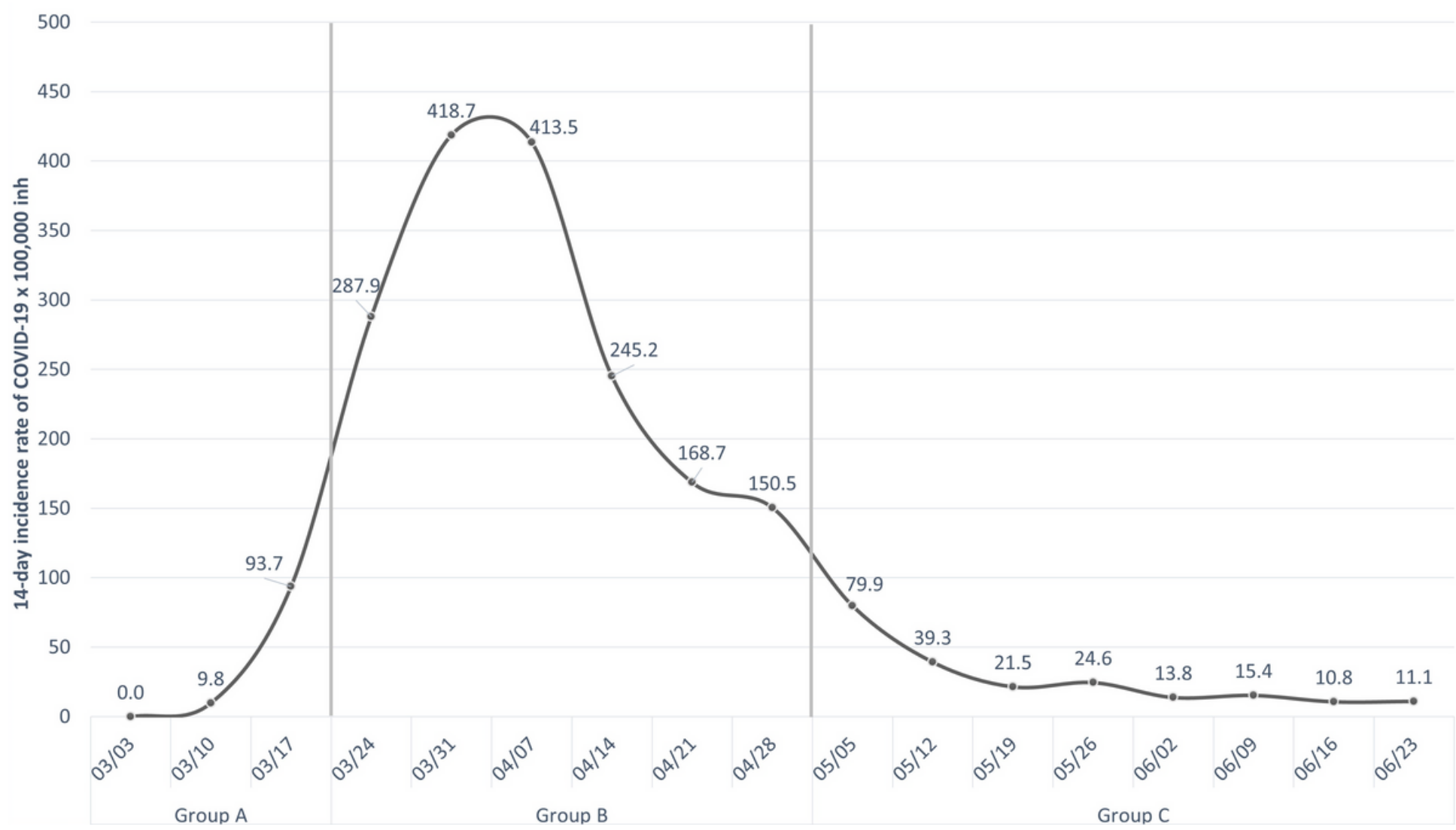

Figure 2

Fourteen-day incidence rate of COVID-19 x 100.000 inhabitants in the Hospital healthcare zones. Group A: from 20 February to 15 March 2020 , group B: from 16 march to 3 May 2020 and group C: from 4 May to 19 June 2020 